\title{
A FORÇA EDUCATIVA E EMANCIPATÓRIA DO MOVIMENTO NEGRO EM TEMPOS DE FRAGILIDADE DEMOCRÁTICA
}

Nilma Lino Gomes

Resumo

O Brasil escondeu e guardou o racismo atrás do discurso da democracia racial, da mestiçagem e da diversidade. Porém, nos tempos de acirramento e recrudescimento da extrema direita, da onda neoconservadora e reacionária, esse mesmo racismo tem sido revelado publicamente e sem constrangimentos. Nesse contexto, existe um ator político central no processo de luta antirracista e de reeducação da sociedade, do Estado e da universidade: o Movimento Negro. Ele é um dos principais protagonistas das lutas por emancipação no decorrer da história política brasileira, a partir do século XX. Nesse processo, o Movimento Negro tem sido produtor de diferentes formas de saberes emancipatórios que podem nos ajudar a reagir diante do atual contexto de incertezas vivido pela sociedade brasileira. Do conjunto de saberes articulados e sistematizados pelo Movimento Negro um deles se destaca nos tempos de democracia em risco: os saberes da indignação.

Palavras-chave: educação; Movimento Negro; democracia

\section{THE EDUCATIONAL AND EMANCIPATORY STRENGTH OF THE BLACK MOVEMENT IN TIMES OF DEMOCRATIC FRAGILITY}

\begin{abstract}
Brazil hid and kept racism behind the discourse of racial democracy, mestizaje and diversity. However, in the times of intensification and resurgence of the extreme right, of the neo-conservative and reactionary wave, this same racism has been revealed publicly and without constraint. In this context, there is a central political actor in the process of antirracist struggle and re-education of society, the state and the university: the black movement. He is one of the main protagonists of the struggles for emancipation in the course of Brazilian political history, starting in the 20th century. In this process, the Black movement has been the producer of different forms of emancipatory knowledge that can help us react to the current context of uncertainty experienced by Brazilian society. Of the set of knowledge articulated and systematized by the Black Movement, one of them stands out in times of democracy at risk: the knowledge of indignation.
\end{abstract}

Keywords: education; black movement; democracy

\section{LA FUERZA EDUCATIVA Y EMANCIPADORA DEL MOVIMIENTO NEGRO EN TIEMPOS DE FRAGILIDAD DEMOCRÁTICA}

Resumen

Brasil ocultó y mantuvo el racismo detrás del discurso de la democracia racial, el mestizaje y la diversidad. Sin embargo, en tiempos de empeoramiento y aumento de la extrema derecha, de la ola neoconservadora y reaccionaria, este mismo racismo se ha revelado públicamente y sin restricciones. En este contexto, hay un actor político central en el proceso de lucha antirracista y la reeducación de la sociedad, el Estado y la universidad: el movimiento negro. Es uno de los principales protagonistas de las luchas por la emancipación a lo largo de la historia política brasileña, desde el siglo XX en adelante. En este proceso, el movimiento negro ha sido productor de diferentes formas de conocimiento emancipatorio que pueden ayudarnos a reaccionar ante el contexto actual de incertidumbre experimentado por la sociedad brasileña. Del conjunto de conocimientos articulados y sistematizados por el Movimiento Negro, uno de ellos destaca en tiempos de democracia en riesgo: el conocimiento de la indignación.

Palabras clave: educación; movimiento negro; democracia 
A luta contra o racismo e as desigualdades raciais, assim como a afirmação da identidade negra são processos complexos, desafiadores e que precisam ser desenvolvidos de forma enfática, persistente e contundente.

Retomar de forma incisiva a urgência da luta antirracista depois de 13 anos de governo democrático (de 2003 ao início de 2016), no Brasil, pode parecer estranho. Afinal, nesse período o país teve na sua estrutura ministerial órgãos responsáveis pelo combate ao racismo, tais como, a Secretaria de Políticas de Promoção da Igualdade Racial (SEPPIR) e, posteriormente, o Ministério das Mulheres, Igualdade Racial e Direitos Humanos (MMIRDH).

Além disso, em nível federal, várias políticas e projetos antirracistas foram realizados, tais como: a alteração da Lei de Diretrizes e Bases da Educação (Lei n. 9.394/1996) pela Lei n. $10.639 / 2003$ ao introduzir a obrigatoriedade do ensino de história e cultura afro-brasileira e africana nos currículos das escolas da educação básica; o Decreto n. 4.887/2003 que regulamentou o procedimento para identificação, reconhecimento, delimitação, demarcação e titulação das terras ocupadas por remanescentes das comunidades dos quilombos de que trata o Art. 68 do Ato das Disposições Constitucionais Transitórias; a Política Nacional de Saúde Integral da População Negra, instituída pela Portaria n. 992 de 13 de maio de 2009; o Estatuto da Igualdade Racial (Lei n. 12.288/2010); a Lei de cotas sociais e raciais nas Instituições Federais de Ensino Superior (IFES) (Lei n. 12.711/2012); a Lei de cotas raciais nos concursos públicos federais (Lei n. 12.990/2014) e a Portaria n. 13/2016 do Ministério da Educação que induziu as cotas raciais na pós-graduação das IFES.

Não há como deixar de reconhecer que a luta antirracista desenvolvida pelo Movimento Negro ganhou, no período dos 13 anos supracitado, um reconhecimento oficial do Estado brasileiro. Várias demandas desse movimento social foram transformadas em políticas públicas.

Então, por que a luta antirracista, no Brasil, se faz ainda tão urgente? Por que não podemos cuidar, manter e aprimorar as políticas de igualdade racial e de ações afirmativas já existentes e, a partir dessas experiências, construir outras muito mais estruturantes e transformadoras?

Porque não estamos em tempos de trégua. Muito pelo contrário, estamos em tempos em que as lutas de classes, antirracista, antipatriarcal ganham outros contornos. Elas se desenvolvem em tempos de ataques ao Estado de Direito construído arduamente pelo campo emancipatório brasileiro ao longo da nossa história política. Todo ataque ao Estado de Direito é uma ação contra as lutas sociais em prol dos direitos, da justiça social e da igualdade. É também um golpe frontal ao antirracismo.

Para aquelas e aqueles que se sabem negras e negros, bem como para os aliados da luta antirracista, de qualquer grupo étnico-racial, que lutam contra o racismo, as desigualdades sociais, raciais e pela democracia, esse alerta nunca é demais.

Desde o dia 31 de agosto de 2016, o Brasil tem vivido uma manobra política conservadora de grupos capitalistas, fundamentalistas, ruralistas, militares apoiados por vários setores do judiciário, da grande mídia e com maioria de representação no Congresso Nacional, que conseguiram impor o impeachment da primeira mulher legitimamente eleita presidenta do Brasil, Dilma Rousseff ${ }^{1}$.

Alves (2016, p. 155) alerta:

\footnotetext{
${ }^{1}$ Em 31 ago. 2016, o Senado Federal aprovou, numa votação em plenário, o impeachment da primeira mulher eleita presidenta do Brasil, Dilma Rousseff. A aprovação aconteceu mesmo sem comprovação de que a então presidenta tivesse cometido crime de responsabilidade fiscal, única possibilidade constitucional para se interromper um mandato presidencial no Brasil. Dessa irregularidade política e jurídica, assumiu o poder executivo um governo considerado ilegítimo que passou a implementar, em articulação com a ala conservadora do Congresso Nacional, uma série de retrocessos nas políticas sociais e nos direitos trabalhistas conquistados pela população brasileira desde o século XX. O país passou a viver tempos duros de realinhamento da política capitalista e neoliberal, apoiado pela grande mídia, empresários, ruralistas e setores do judiciário.
} 
O golpismo, como golpismo, é um ingrediente visceral da cultura política e social brasileira. Faz parte da pulsão histórica brasileira, onde oligarquias políticas regionais se perpetuam no campo e na cidade, atualizando a estrutura de classe e o poder político de extração colonial-escravista. À sombra do poder oligárquico, vivem os homens livres e as camadas médias, políticos, intelectuais e bacharéis, juízes e jornalistas a serviço dos donos do Poder e do Dinheiro.

A partir do ano de 2016, o Brasil vive tempos de muitas incertezas e ataques à institucionalidade democrática. Incertezas políticas diante de um impeachment que, hoje, comprovadamente, foi um duro golpe parlamentar que incidiu sobre a sociedade brasileira e as conquistas das lutas sociais desencadeadas, principalmente, após a queda da ditadura militar instaurada nos anos 1960 e derrotada nos anos 1980. Incertezas diante das investidas de aniquilamento dos direitos garantidos aos trabalhadores e trabalhadoras desde os anos 1930 e aprimorados na Constituição Federal de 1988. Incertezas econômicas diante de um capitalismo internacional realinhado e opressor; incertezas culturais diante do crescimento da cultura do ódio, da intolerância e do medo; incertezas sociais diante do aumento da pobreza, das desigualdades e da violência; incertezas educacionais diante de retrocessos nas políticas educacionais, da vigilância conservadora e autoritária no que se refere às questões de gênero, diversidade sexual e raça; incertezas emocionais diante da força psicológica e destruidora do racismo, principalmente, sobre a autoestima de tantas crianças, jovens e adultos negros e pobres; incertezas religiosas diante do ataque neopentecostal às religiões de matriz afro-brasileira.

Tempos de EC 95/2016, que congela por 20 anos os recursos públicos destinados, principalmente, para a saúde, educação, assistência social e segurança pública. Uma ofensiva conservadora de retirada dos direitos sociais tendo como alvo as conquistas democráticas da Constituição de 1988.

De acordo com Mariano (2017, p. 278-279):

Dessa forma, independentemente das opções político-partidárias (e para além delas), é preciso que a sociedade civil brasileira tome consciência de que o plano econômico traduzido pela EC 95/2016 afronta o projeto político e constituinte de 1988, referendado nas últimas eleições presidenciais de 2014. A EC 95/2016 não foi, afinal, o projeto político e constitucional vencedor nestas últimas eleições. Um vice-presidente alçado à condição de presidente, por um impeachment ou um golpe, qualquer que seja a narrativa, não poderia impor agora um novo regime fiscal que represente, como a EC 95/2016 o faz, um projeto político constituinte diametralmente oposto ao de 1988, não vencedor nas urnas. Por conseguinte, além de suas inconstitucionalidades, infelizmente afastadas pelo Supremo Tribunal Federal no MS 34.448-MC/DF, a EC 95/2016 padece de legitimidade democrática, sendo ainda um projeto desastroso de solução de uma crise econômica, e aparentemente motivado para sabotar os avanços do país na implementação de um Estado de Bem Estar Social e de uma economia mais soberana e independente, outrora capaz de influenciar a consolidação de um projeto de autonomia de toda a América latina e de seus povos.

Vivemos também tempos de aumento do desemprego e do trabalho informal, do aumento dos assassinatos de lideranças quilombolas, indígenas e de defensores dos direitos humanos, de ataques ao meio ambiente, de reforma trabalhista, de lei da terceirização, de reforma da previdência, de privatização, da proposta conservadora de uma Escola Sem Partido, de aumento da LGBTfobia, de ataque aos direitos humanos, do genocídio da juventude negra, de aumento do feminicídio.

Os tempos de incertezas que vivemos no ano de 2016 foram acirrados após as eleições de 2018. O Brasil e o mundo assistiram a vitória do candidato de extrema direita nas eleições presidenciais, apoiado pelos militares, empresários, ruralistas, neopentecostais, milicianos, grande 
mídia e setores do judiciário. Os mesmos atores que apoiaram direta ou indiretamente o impeachment da presidenta Dilma Rousseff e o governo interino ilegítimo que se constitui após esse ato brutal continuaram a sua ação política nefasta. A forma como o impeachment se desenvolveu tem sido considerada por vários estudiosos do campo do direito e da política como um golpe de Estado.

Bercovici (2016, p. 145) afirma:

Não necessitamos de sofismas ou de exercícios retóricos para disfarçar a realidade. Impeachment sem fundamento jurídico nada mais é do que um golpe de Estado. Um golpe patrocinado por parcela do Poder Legislativo, o que não lhe confere legitimidade alguma. Não interessa de onde se origina, podendo ser proveniente do Poder Legislativo, de um tribunal, palácio ou quartel, tampouco interessa a denominação que se queira dar, a natureza das coisas não muda: golpe é golpe.

Para quem luta cotidianamente contra o racismo, os tempos sempre foram de incerteza diante da capacidade de a sociedade brasileira rever a si mesma e jogar fora o seu racismo. Uma sociedade que esconde e guarda o racismo atrás do discurso da democracia racial, da mestiçagem, da diversidade, mas, que sempre o revela publicamente quanto mais se acirram os tempos de recrudescimento da direita, da onda neoconservadora e reacionária. Quanto mais a democracia é colocada em risco.

Não vivemos apenas tempos de incertezas, no entanto. A cada incerteza vivida certezas amadurecem e se fazem vivas. Talvez a maior delas é o quanto se faz necessário a tomada de consciência, a afirmação e a construção de uma solidariedade e de uma maior articulação entre as vítimas do racismo e das mais variadas desigualdades sociais, possibilitando uma forte reação antirracista, anticapitalista, antipatriarcal e emancipatória.

Para as negras e os negros brasileiros que lutam por democracia, soma-se a essa certeza o fato de que somos sujeitos da diáspora africana e o Brasil é nossa terra por conquista e por direito. Nele construímos, enraizamos e expandimos a nossa afro-brasilidade. Sim, acredito que existe um jeito negro de ser, de viver, de fazer política, arte, cultura, música, educar e produzir conhecimento. Isso não é essencialismo. É construção histórica, cultural, política e ancestral.

A certeza de que nós, negras e negros brasileiros, construímos e produzimos afrobrasilidade(s) não foi e nem é aprendida na escola básica e nem no ensino superior. Ela tem sido ensinada e aprendida no contexto das lutas sociais antirracistas e tem como protagonista as diversas formas de luta e resistência negras. Dentre elas, destaco a ação, as reivindicações, as denúncias e a luta do Movimento Negro brasileiro.

\section{A FORÇA EDUCATIVA DO MOVIMENTO NEGRO}

No contexto da luta antirracista, alguns autores e autoras advertem que, todas e todos, direta ou indiretamente, fomos e somos educados e reeducados pelo Movimento Negro, no Brasil. Negros, brancos, indígenas, descendentes dos asiáticos, árabes, judeus e outros povos do mundo que vivem em nosso país, aprendemos e reaprendemos sobre a luta antirracista - quer concordemos ou não com ela - por meio da ação pedagógica do Movimento Negro, o qual é herdeiro das muitas lutas das africanas e africanos escravizados no Brasil, bem como das primeiras formas de associações e organizações negras pós-abolição e do início do século XX.

Entende-se como Movimento Negro:

[...] as mais diversas formas de organização e articulação das negras e dos negros politicamente posicionados na luta contra o racismo e que visam à superação desse perverso fenômeno na sociedade. Participam dessa definição os grupos políticos, acadêmicos, culturais, religiosos e artísticos com o objetivo explícito de 
superação do racismo e da discriminação racial, de valorização e afirmação da história e da cultura negras no Brasil, de rompimento com as barreiras racistas impostas aos negros e às negras na ocupação dos diferentes espaços e lugares na sociedade. Trata-se de um movimento que não se reporta de forma romântica à relação entre os negros brasileiros, a ancestralidade africana e o continente africano da atualidade, mas reconhece os vínculos históricos, políticos e culturais dessa relação, compreendendo-a como integrante da complexa diáspora africana. Portanto, não basta apenas valorizar a presença e a participação dos negros na história, na cultura e louvar a ancestralidade negra e africana para que um coletivo seja considerado como movimento negro. É preciso que nas ações desse coletivo se faça presente e de forma explícita uma postura politica de combate ao racismo. Postura essa, que não nega os possíveis enfrentamentos no contexto de uma sociedade hierarquizada, patriarcal, capitalista, LGBT fóbica e racista (GOMES, 2017, p. 2324).

A interpretação da raça como estrutural e estruturante para se compreender a complexidade do quadro de discriminação e desigualdades no Brasil, realizada pelo Movimento Negro, aos poucos, passou a ocupar espaço nas análises sociológicas e entre os formuladores de políticas públicas. Sueli Carneiro (2002, p. 7) argumenta que "[...] os atuais dados da desigualdade racial conferem autoridade às denúncias dos movimentos negros contemporâneos sobre as diferenças de direitos e oportunidades existentes em nossa sociedade em prejuízo da população negra".

Luiz Alberto Oliveira Gonçalves e Petronilha Beatriz Gonçalves e Silva (2000, p. 105) afirmam: "[...] sem esse ator coletivo jamais teríamos pautado o tema do racismo e da discriminação étnico-racial nas agendas políticas e da justiça brasileira".

O Movimento Negro é educador, um ator coletivo e político que reeduca e emancipa a sociedade, a si próprio e ao Estado, produzindo novos conhecimentos e entendimentos sobre as relações étnico-raciais e o racismo no Brasil, em conexão com a diáspora africana.

Articulados às práticas e intervenções do Movimento Negro e sendo reeducados direta ou indiretamente por ele, também é possível encontrar, no Brasil, vozes e corpos negros anônimos que atuaram e ainda atuam na superação do racismo e na afirmação das identidades, dos valores, do trabalho, da cultura e da vida da população negra. São as negras e os negros em movimento. Todos são, de alguma forma, herdeiros da sabedoria e dos ensinamentos do Movimento Negro.

No reconhecimento do Movimento Negro como educador, Gomes (2017) organiza o seu legado epistemológico intrínseco, como produtor de um tipo específico de conhecimento: o conhecimento nascido na luta. Um conhecimento que quanto mais se consolida, mais tem a capacidade de transformar a sua própria forma de perceber e interpretar os problemas que motivam a sua luta. Um conhecimento que se organiza na forma de produção intelectual e de práticas políticas, sociais e pedagógicas.

A essa organização político-epistemológica a autora supracitada denomina saberes ou conhecimentos emancipatórios produzidos historicamente pela população negra, articulados e sistematizados pelo Movimento Negro.

Esses saberes / conhecimentos têm provocado transformações na sociedade brasileira. É importante lembrar, retomar, analisar e enfatizar com orgulho esses saberes / conhecimentos, pois eles fazem parte da nossa história de luta contra o racismo e em prol da igualdade e da democracia. As negras e os negros que lutam contra o racismo, fazem parte dessa história e são produtores desses saberes / conhecimentos. 
DOI: $10.12957 /$ teias. $\%$ Y.49715

SABERES EMANCIPATÓRIOS: MANTENDO ACESA A CHAMA DA ESPERANÇA E DA LUTA

É de suma importância retomar e enfatizar esses saberes / conhecimentos para que a nossa chama de esperança não se apague e o nosso sentimento de indignação diante das injustiças não nos imobilize, mas nos redirecione rumo à construção de outros caminhos políticos e pedagógicos e de novas estratégias na luta democrática e antirracista.

Discutamos, então, um pouco sobre esses saberes / conhecimentos, inspirados nas reflexões construídas por Gomes (2017; 2018).

\section{Os saberes identitários}

O Movimento Negro, principalmente no contexto das ações afirmativas, recolocou o debate sobre a raça no Brasil. Mesmo com críticas, houve um aumento da institucionalização do uso das categorias de cor do IBGE nos formulários de identificação das instituições e nos censos, trazendo a autodeclaração racial para o universo e para o cotidiano dos brasileiros. O debate sobre quem é negro e quem é branco invade a vida das brasileiras e dos brasileiros de uma forma diferente extrapolando os espaços da militância e da discussão política.

Assistimos, nas redes sociais, a uma profusão de páginas pessoais, de figuras públicas, artistas e de grupos juvenis publicadas por pessoas negras que escrevem sobre a experiência de ser negro, denunciam o racismo, transmitem informações, dão dicas de beleza e cuidados com a pele e o cabelo crespo. Discussões como apropriação cultural, colorismo, racismo, ações afirmativas são realizadas na vida online e off-line de maneira crítica, política e posicionada por um maior número de sujeitos negros.

Uma nova visibilidade da questão racial e da identidade negra, de forma afirmativa, se faz presente na literatura, nas artes, no cinema, no teatro, no campo do conhecimento. Os diferentes grupos do Movimento Negro passaram a ganhar mais espaço na cena pública e política afirmando a identidade negra e sua complexidade, inclusive, no campo político-partidário.

Questões como a violência contra a mulher negra e o genocídio da juventude negra que fazem parte das denúncias históricas do Movimento Negro passaram a ser incorporadas, mesmo que ainda lentamente, nas preocupações de pesquisadores, ONGs e poder público. O recorte raça / cor passa a ser inserido como uma categoria de análise importante para se compreender a realidade de gênero, juvenil, de trabalho, regional e de pobreza no Brasil. Os dados alarmantes desvelados pelos estudos realizados com esse recorte comprovam as denúncias do Movimento Negro. A identidade negra passa a ser tematizada de um outro lugar. Aos poucos, o Brasil vai compreendendo que ser negro e negra e afirmar-se como tal é um posicionamento político e identitário que causa desconforto nas elites e nos poderes instituídos e que o uso da força e da violência, uma das estratégias antigas do racismo, tem sido uma tentativa de fazê-los calar.

O Movimento Negro tem conseguido expandir a politização da raça e da identidade negra para lugares nos quais elas antes não eram consideradas ou eram invisibilizadas.

\section{Os saberes políticos}

A universidade, os órgãos governamentais passaram a tematizar sobre as desigualdades raciais. As pesquisas e políticas educacionais, os indicadores de avaliação escolar, o campo da antropologia, da sociologia, da história e da saúde começam a dar um outro destaque à questão racial. O campo do direito começa a ser pressionado para dar respostas que contemplem a justiça social e a diversidade. As universidades começam a construir comissões de heteroidentificação inter(multi)raciais para conter as fraudes na aplicação da Lei n. 12.711/2012, Lei de cotas. 
O debate político sobre a raça é recolocado no Brasil em outros moldes, trazendo à cena pública posições que desde a ditadura pareciam ter sido superadas e desvelando que algumas heranças do racismo científico permanecem até hoje, mesmo entre os intelectuais considerados progressistas.

A raça, na sua concepção ressignificada, passa a ser um critério para superar desigualdades, por meio da adoção de políticas públicas institucionalizadas por lei.

A ressignificação desse conceito pelo Movimento Negro reeducou a sociedade e o campo teórico a não usá-lo:

[...] com um sentido reduzido e tradicional, ou seja, que os grupamentos sociais com características biológicas semelhantes, geralmente transmitidas por hereditariedade e que são visíveis a olho nu como: a cor da pele, o tipo de cabelo, entre outros, são superiores ou inferiores entre si. Abandona-se o determinismo biológico que perpassa o termo e o redimensiona com uma perspectiva política. Entendo raça como um conceito relacional, que se constitui historicamente e culturalmente, a partir de relações concretas entre grupos sociais em cada sociedade. (GOMES, 1995, p. 49).

As intelectuais negras e negros se organizam, em 2000, e fundam a Associação Brasileira de Pesquisadores Negros $(\mathrm{ABPN})^{2}$, a qual é responsável pela realização bienal dos Congressos Brasileiros de Pesquisadores e Pesquisadoras Negros (COPENE) e dos COPENES regionais. Nas universidades e faculdades, organizam-se Núcleos de Estudos Afro-Brasileiros (NEABs), responsáveis pela realização de pesquisas, extensão, formação de professores, pelos debates políticos e acadêmicos sobre a questão racial brasileira e sobre a África.

A questão racial passa a ocupar um outro lugar político no campo da produção do conhecimento e, aos poucos, as instituições de ensino superior começam a inserir História da África, relações étnico-raciais e diversidade, gênero e relações étnico-raciais como disciplinas optativas, eletivas e obrigatórias nos currículos, demandando concursos públicos específicos para essa área. Além disso, por meio da aplicação da Lei n. 12.990/2014, algumas instituições públicas começaram a realizar concursos para docentes do ensino superior reservando vagas para candidatos negras e negros.

Algumas universidades já realizam as cotas na pós-graduação, em atendimento à Portaria Normativa n. 13/2016, do Ministério da Educação. Para cumprir com a legislação e garantir os direitos da população negra às ações afirmativas gestores, intelectuais, profissionais de várias áreas necessitam conhecer mais sobre a temática racial e são obrigados a revelar sua ignorância e recorrer àquelas e àqueles que têm competência e expertise sobre o assunto. Nesse momento, intelectuais, pesquisadoras, pesquisadores e ativistas do Movimento Negro são chamados a opinar. Os saberes políticos construídos pela população negra e sistematizados pelo Movimento Negro entram em ação, dialogando com os outros saberes e ignorâncias.

Contra o racismo epistêmico, há, aos poucos, o reconhecimento de que as negras e os negros são sujeitos políticos e de conhecimento e têm competência para falar sobre a questão racial, no Brasil, e sobre os mais variados temas.

O Movimento de Mulheres Negras merece destaque quando refletimos sobre os saberes políticos. A ação das ativistas negras constrói saberes e aprendizados políticos, identitários e estéticos-corpóreos específicos. As ativistas negras indagam o machismo dentro do próprio Movimento Negro e desafiam os homens ativistas a repensarem, mudarem de postura e de atitude nas suas relações políticas e pessoais com as mulheres. Denunciam a violência machista dentro do próprio Movimento Negro e demais movimentos sociais, nas relações domésticas, nas disputas

2 Para saber mais sobre a ABPN e o CONEAB consulte o site www.abpn.org.br . 
internas quer sejam no emprego, nos movimentos, nos sindicatos e nos partidos. Elas reeducam o próprio feminismo, aos homens e mulheres brancos, de outros pertencimentos étnico-raciais e a elas mesmas.

O protagonismo das mulheres negras, no Brasil, assumiu um destaque quando da realização da Marcha Nacional das Mulheres Negras 2015 contra o Racismo e pelo Bem Viver, no dia 18 de novembro, em Brasília.

\section{Os saberes estéticos-corpóreos}

A partir do ano 2000, há uma politização da estética negra diferente do final dos anos 1970 e início dos 1980 e 1990 do século XX.

A estética negra passou a ser compreendida como parte do direito da cidadania e da vida das mulheres e homens negros. Ela se faz presente de forma mais pública e contundente a partir do advento das políticas de ações afirmativas. Essas políticas reeducam as negras e os negros na sua relação com o corpo e, também, reeducam a sociedade brasileira no seu olhar sobre o corpo negro.

Com as políticas de ações afirmativas, configurou-se também um outro perfil de juventude negra que passa a se afirmar mais por meio da estética e da ocupação de lugares acadêmicos e sociais. Juventude essa, na sua maioria periférica, e que aprendeu a ter orgulho de ser negro e da periferia, numa postura afirmativa e realista.

Essa juventude, principalmente as mulheres, realiza marchas do Orgulho Crespo, ações como o Encrespa Geral, eventos de empoderamento crespo, páginas específicas no Facebook, programas no Youtube, blogs e tutoriais de beleza negra. Compreendem como o corpo e o cabelo são importantes símbolos de construção da identidade negra. Politizam, do seu jeito, o conceito de beleza negra.

Os saberes estéticos-corpóreos também fazem parte de uma série de lutas e ensinamentos das mulheres negras. Numa articulação internacional, as mulheres negras ativistas construíram politicamente o Dia da Mulher Afrolatinoamericana e Afrocaribenha, dia 25 de julho. No Brasil, essa data ganhou uma amplitude institucional e passou a fazer parte do processo de reeducação do Estado brasileiro em relação ao reconhecimento da luta das mulheres negras.

Um dos resultados desse processo foi a sanção presidencial da Lei n. 12.987, de 2 de junho de 2014, decretando o Dia Nacional de Tereza de Benguela e da Mulher Negra, a ser comemorado, anualmente, em 25 de julho.

\section{O ATAQUE DA EXTREMA DIREITA À LUTA ANTIRRACISTA}

Como vivemos tempos de incertezas e antidemocráticos todo esse acúmulo de saberes / conhecimentos construídos pelas negras e pelos negros na história brasileira, sistematizados e articulados em reivindicação por direitos, pelo Movimento Negro, está sob forte ataque.

O governo federal de extrema direita que assumiu o poder executivo, em 2018, instaurou junto com os seus apoiadores espalhados nas diversas instituições e regiões do país, um clima de ataque a tudo o que pode ser considerado democrático e emancipatório. Lutar por direitos e emancipação social no Brasil, de hoje, passa a ser uma ação sob suspeita. Uma suspensão contaminada pela lógica militar / capitalista / neopentecostal a ponto de o fato de uma pessoa se afirmar como defensora da democracia, da igualdade e da justiça social tornar-se sinônimo de ser comunista, porém, de maneira ideologicamente deturpada.

No caso das políticas da igualdade racial, o Ministério das Mulheres, Igualdade Racial e Direitos Humanos foi extinto, o Conselho Nacional de Promoção da Igualdade Racial (CNPIR) 
foi desestruturado, o genocídio da juventude negra sequer é discutido pelo atual Ministério da Justiça e Segurança Pública e o feminicídio negro não ocupa lugar nas preocupações da atual Secretaria Nacional de Políticas para as Mulheres, órgão do Ministério da Mulher, da Família e dos Direitos Humanos. Somado a isso, a Fundação Cultural Palmares, órgão do extinto Ministério da Cultura transformado em Secretaria Nacional de Cultura, é assumida por um homem negro, de extrema direita, que ataca publicamente o Movimento Negro e a luta antirracista, desconsiderandoos e despolitizando suas ações e conquistas ${ }^{3}$.

Além disso, o apoio explícito do atual governo aos militares tem autorizado ainda mais a ação violenta das forças de segurança pública contra a população pobre, negra, jovem nas periferias, nos bailes funks, nos morros e favelas. Ostensivamente, os policiais usam ainda mais a força e a violência contra as manifestações políticas de rua, festivas e nas abordagens individuais.

As universidades sofrem com uma política de "contenção de gastos", intervenção na escolha dos seus dirigentes e as instituições de ensino, de um modo geral, são ideologicamente atacadas como espaços de produção de ideias comunistas. As escolas cívico-militares têm sido instituídas na educação básica pública .

Nesse contexto, a política de cotas raciais nas universidades passa a ser contestada ainda mais e deformada como paternalismo do Estado. Já é possível encontrar no Congresso Nacional, projetos que propõem o seu fim. Todo esse discurso acaba por inflamar os setores conservadores e de extrema direita no país, da elite até os pobres.

Vivemos um momento em que os saberes / conhecimentos sistematizados pelo Movimento Negro brasileiro são indagados, deturpados e reinterpretados pelas forças conservadoras, de extrema direita e pela afro-direita que antes parecia invisível, mas sempre existiu. Contra os saberes aqui apresentados ignorâncias vêm sendo produzidas pelo racismo, pelo neoliberalismo e pelo neofascismo. E sãos essas ignorâncias que hoje ocupam lugar de poder no plano da política macro.

Os saberes / conhecimentos emancipatórios construídos pelas negras e negros na luta antirracista tensionam as ignorâncias identitárias, políticas e estéticas-corpóreas construídas nesses tempos de incertezas. É uma luta social, simbólica, política e identitária complexa e tensa que nem sempre se faz visível e nem ocupa as principais preocupações das nossas análises sobre a crise democrática.

\footnotetext{
3 O jornalista Sérgio Nascimento de Camargo foi nomeado nesta quarta-feira (27 mar. 2020) como novo presidente da Fundação Palmares, órgão responsável por promover a cultura de matriz africana, ocupando o lugar de Vanderlei Lourenço. Em seu perfil no Facebook, Camargo se define como: "Negro de direita, contrário ao vitimismo e ao politicamente correto". Ele já afirmou, em sua conta, que o Brasil tem "racismo nutella" e que "racismo real existe nos EUA". Camargo, que usa a rede social com frequência, também escreveu que a escravidão foi terrível "[...] mas benéfica para os descendentes". Na sequência, diz que "[...] negros do Brasil vivem melhor que os negros da África". Em outra publicação, no dia 20 de novembro, ele chama de "vergonha" o Dia da Consciência Negra e afirma que ele "[...] precisa ser combatido incansavelmente até que perca a pouca relevância que tem". Camargo continua dizendo que se trata de um "[...] feriado político, instituído pela esquerda com o objetivo de propagar o revanchismo histórico". Um dia depois, o jornalista diz que "[...] cotas raciais para negros são mais do que um absurdo". A nomeação faz parte de uma mudança no quadro da cultura, iniciada semanas após Roberto Alvim assumir a subpasta, hoje subordinada ao Ministério do Turismo (www.otempo.com.br) (Acesso em 28 mar. 2020).

4 O Programa Nacional das Escolas Cívico-Militares é uma iniciativa do Ministério da Educação, em parceria com o Ministério da Defesa, que apresenta um conceito de gestão nas áreas educacional, didático-pedagógica e administrativa com a participação do corpo docente da escola e apoio dos militares. A proposta é implantar 216 Escolas CívicoMilitares em todo o país, até 2023, sendo 54 por ano (www.escolacivicomilitar.mec.gov.br. Acesso em 27 mar. 2020).
} 


\section{PARA FINALIZAR: O MOVIMENTO NEGRO E OS TEMPOS DE INCERTEZAS}

À medida que o Movimento Negro aprimora a sua luta por emancipação social e pela superação do racismo, mais se intensifica a variedade de formas de opressão e de dominação contra as quais ele tem que se contrapor, bem como se amplia a multiplicidade de escalas (local, nacional e transnacional) das lutas em que ele se envolve (SANTOS, 2006).

O Movimento Negro, na sua configuração complexa e dinâmica, é desafiado a produzir novos conhecimentos e fronteiras de resistência em tempos de incertezas e de golpe.

Em tempos de incertezas, é preciso construir uma resistência democrática antirracista radical e novas fronteiras de conhecimento. É preciso ampliar a nossa capacidade de indignação, aumentar a solidariedade, diminuir disputas e superar a arrogância de quem sabe melhor analisar a situação em que vivemos e apontar a melhor saída.

Aos intelectuais, é o momento de provar que é possível produzir conhecimento junto com e não sobre as pessoas, sociedade e a vida, sobretudo, aquelas e aqueles que mais sofrem. Somos chamados a produzir uma outra forma de conhecimento.

Nos últimos meses, venho analisando um outro conjunto de saberes / conhecimentos sistematizados pelo Movimento Negro e que se destaca ainda mais nos momentos de acirramento do racismo, das desigualdades e da violência: os saberes / conhecimentos indignação. É também um tipo de conhecimento emancipatório. Ele é inconformado, antirracista, antipatriarcal, anticapitalista e construído pela dignidade daqueles e daquelas que lutam contra a opressão.

Inspirados pela afirmação de que os movimentos sociais são educadores, Gomes (2017) e Arroyo (2003) constroem pedagogias, refletimos que os saberes / conhecimentos indignação, embora construídos na luta contra as desigualdades, não se confundem com a Pedagogia do Oprimido formulada por Paulo Freire, pois são forjados não somente na luta contra a superação das desigualdades sociais. Reconhecendo o peso que tais desigualdades assumem na vida das brasileiras e brasileiros, o foco desses saberes vai além: ele visibiliza e tem como eixo central a luta contra a opressão racial.

A opressão racial se dá intrinsecamente articulada com a classe social, mas a atravessa e atinge todos os corpos negros e a herança ancestral africana inscritos na pele das pessoas, na sua corporeidade, independentemente da classe social a que pertençam. A forma como a opressão racial opera resulta num acúmulo opressor no qual também estão a classe, o gênero e a orientação sexual.

Essa complexa imbricação opressora pode até nos dar a impressão de que o racismo é atenuado de acordo com o nível socioeconômico, a escolaridade, o cargo ocupado, a visibilidade social, artística, política, esportiva da pessoa negra. É assim que o racismo engana a todos nós: quando ele nos faz pensar que é um fenômeno passível de ser atenuado. Fenômenos perversos podem se metamorfosear e nos parecer camuflados e secundários, mas a sua ação nefasta na vida e na identidade das suas vítimas jamais é atenuada.

Os saberes / conhecimentos indignação se articulam e se expressam por meio do par dignidade / indignidade. Quanto mais indignas forem as situações, as condições e a forma do racismo se impor aos negros e às negras, mais a dignidade dessas pessoas é atingida. Muitas vezes isso resulta em atitudes de isolamento, mas, em outras, pode resultar em um renascer políticoidentitário. E, dessa forma., produzir novos enfrentamentos e uma maneira corajosa de lutar pela recuperação da dignidade roubada.

Produzidos historicamente pela população negra, no Brasil, na sua trajetória de sofrimento e de resistência, os saberes / conhecimentos indignação se afirmam por meio de gestos, memórias, reconhecimento de personalidades negras omitidas pela história, afirmação da religiosidade afrobrasileira, dos ensinamentos da capoeira, das artimanhas quilombolas para sobreviver e lutar contra a opressão ruralista, da valorização da infância negra. Eles se fazem presentes nas ações dos 
estudantes negros secundaristas e universitários que demandam a inclusão de intelectuais negros e negras nos currículos, nas ocupações das escolas, nas ocupações urbanas, na tensão provocada por ativistas negras e negros nos partidos de esquerda reivindicando representatividade negra nos cargos de poder e decisão, na produção de sites, páginas do Facebook e Instagram por lideranças negras de diferentes gerações. Também podem ser vistos na atuação das youtubers negras e negros, nas novas articulações do Movimento Negro construindo fóruns inter-entidades, no Hip Hop, no slam, nas revoltas da população atingida pela violência policial, nas passeatas e atos denunciando o racismo, o machismo e a violência, como por exemplo, no caso do assassinato da vereadora negra Marielle Franco, no Rio de Janeiro.

Esse conjunto de saberes / conhecimentos transformam a denúncia do racismo em uma efervescência e articulação nacional e internacional. Podem ser vistos na presença de negras e negros com consciência racial na política institucional, na atuação do feminismo negro, e no Mulherismo Africana 5 .

No momento atual cabe-nos a pergunta: como o Movimento Negro tem articulado e sistematizado esses saberes / conhecimentos / indignação? Como ele tem sido reeducado por esses saberes em tempos de incertezas e de ataques ao Estado de Direito? O Movimento Negro tem mobilizado a sua capacidade de ampliar a sua intervenção na sociedade e nas relações de poder e transformado esses saberes / conhecimentos em estratégias de enfrentamento ao racismo exacerbado em tempos de neofascismo?

$\mathrm{Na}$ minha opinião, traduzir em ação política a dignidade que atravessa a história de resistência do povo negro é a chave para que o Movimento Negro saiba sistematizar, articular e transformar em estratégia de luta os saberes / conhecimentos indignação, em tempos de democracia em risco, como o atual momento vivido pelo Brasil.

Mobilizar os sentimentos de dignidade e de indignação transformando-os em uma ação política que se contraponha ao racismo, ao neoliberalismo, ao fundamentalismo religioso, ao patriarcado, a LGBTfobia e ao neofascismo significa lidar com emoções que se manifestam ora de forma mais agressiva e contundente, ora mais negociadora e pacífica diante da perversidade do humano.

O resultado social e político da imbricação dignidade / indignidade presente nos saberes / conhecimentos indignação é um dos desafios do novo ciclo do Movimento Negro do Século XXI. É um ciclo em que se faz necessária a articulação entre os saberes já construídos e os novos aprendizados políticos diante da rápida adesão de muitos setores da população brasileira, inclusive negros, aos ataques democráticos desferidos contra tantos direitos construídos na nossa história social e política.

Essa situação provoca o Movimento Negro da atualidade a encontrar novas formas de diálogo e novas estratégias para articular e sistematizar os saberes / conhecimentos indignação e, junto com outras forças progressistas, se contrapor ao Estado autoritário que a extrema direita intenciona construir desde que chegou ao poder executivo, em 2018. Diferentemente dos outros saberes emancipatórios (identitários, políticos, estéticos-corpóreos) sistematizados pelo

\footnotetext{
${ }^{5}$ De acordo com Ribeiro (2019): Mulherismo Africana trata-se de uma proposição política emancipatória pensada pela $\mathrm{Dr}^{\text {a }}$. Clenora Hudson, que ao pesquisar o lugar participativo das mulheres africanas na história, identificando nessas mulheres o lugar de poder, sabedoria, ensinamentos e luta, encontrou um lugar de quem sempre esteve à frente da agência de seu povo, de matriarca, de geradora de potências. O Mulherismo Africana trata-se de uma perspectiva emancipatória da população preta pensada por mulheres pretas e suas dores frente ao racismo e não uma ação política de liberdade de um determinado segmento. Pensar apenas pela via do gênero não dá conta da desintegração ontológica das mulheres pretas e de seu povo. A proposta do Mulherismo passa por pensar o lugar das mulheres pretas a partir de nós e não nos nutrir de ideologias embrionariamente não direcionadas às mulheres pretas. (https://almapreta.com/editorias/o-quilombo/mulher-preta-mulherismo-africana-e-outras-perspectivas-de-dialogo. Acesso em 28 mar. 2020).
} 
Movimento Negro do século XX (GOMES, 2017) e que foram capazes de reeducar o Estado, a sociedade, a universidade, os saberes / conhecimentos indignação advertem para o quanto um Estado autoritário não é reeducável. Antes, ele precisa ser combatido e derrotado, pois somente um Estado Democrático e de Direito possibilita aprendizagens emancipatórias mútuas, direitos, equidade e justiça social.

\section{REFERÊNCIAS}

ALVES, Giovanni. A pulsão golpista na miséria política brasileira. In: PRONER, Carol et al. A resistência ao golpe de 2016. Bauru: Canal 6, 2016.

ARROYO, Miguel G. Pedagogias em movimento - o que temos a aprender com os movimentos sociais? In: Curriculo sem Fronteiras, v. 3, n. 1, p. 28-49, jan./jun. 2003.

BERCOVICI, Gilberto. O golpe do impeachment. In: PRONER, Carol et al. A resistência ao golpe de 2016. Bauru: Canal 6, 2016.

CARNEIRO, Sueli. Prefácio. In: HENRIQUES, Ricardo. Raça e cor nos sistemas de ensino. Brasília, Distrito Federal: Unesco, 2002. p. 7-10.

GOMES, Nilma Lino. Por uma indignação antirracista e diaspórica: negritude e afro-brasilidade em tempos de incertezas. Revista $A B P N$, v. 10, n. 26, p. 111-124, jul./out. 2018. Disponível em www.abpn.org. Acesso em 20 fev. 2020.

GOMES, Nilma Lino O Movimento Negro educador. Petrópolis: Vozes, 2017.

GOMES, Nilma Lino. Saberes construídos nas lutas por emancipação. In: GOMES, Nilma Lino O Movimento Negro educador. Petrópolis: Vozes, 2017.

GOMES, Nilma Lino. A mulher negra que vi de perto: o processo de construção da identidade racial de professoras negras. Belo Horizonte: Mazza Ed., 1995.

GONÇALVES, Luiz Alberto Oliveira; SILVA, Petronilha Beatriz Gonçalves e. Movimento negro e educação. Revista Brasileira de Educação, n. 15, p. 134-158, set./dez. 2000, São Paulo.

MARIANO, Cynara Monteiro. Emenda constitucional 95/2016 e o teto dos gastos públicos: Brasil de volta ao estado de exceção econômico e ao capitalismo do desastre. Revista de Investigações Constitucionais, v. 4, n. 1, p. 259-281, jan./abr. 2017, Curitiba. Acesso em 28 mar. 2020.

RIBEIRO, Katiuscia. Mulher preta, mulherismo africana e outras perspectivas de diálogo. In: https://almapreta.com/editorias/o-quilombo/. Acesso em 28 mar. 2020.

SANTOS, Boaventura de Sousa. A gramática do tempo: para uma nova cultura política. São Paulo: Cortez, 2006.

Submetido em marco de 2020

Aprovado em julbo de 2020

\section{Informações da autora}

Nilma Lino Gomes

Professora Titular Emérita da Faculdade de Educação da Universidade Federal de Minas Gerais (UFMG)

E-mail: nilmalinogomes@gmail.com

ORCID: 0000-0002-0767-2008

Link Lattes: http//lattes.cnpq.br/7444449891704854 